Many psychiatric services have started "Moditen clinics" in general hospitals or day centres. In some of these treatment has gradually been left to persons whose sole function is to give the patient an injection every fortnight and check, perhaps, that no overt extrapyramidal symptoms have appeared since the last treatment. In these circumstances the appearance of psychiatric symptoms or side-effects may be ignored or missed. The same thing may happen when a general practitioner is requested to administer the drug. In the belief that the psychiatrist continues to supervise the treatment he may restrict himself to giving the injection. It appears essential, therefore, to keep the patient who is on intramuscular fluphenazine under careful supervision. Provided that there is this scrupulous follow-up, there appears to be no contraindication to continuing fluphenazine injection to those patients who have previously shown a depressive reaction to the drug. Relatives can be enlisted to help in this supervision, and they can be instructed to watch for external signs indicative of a depressive mood swing, particularly in the days following the injection. In the series studied both patients and relatives have attended the outpatient department for group instruction and discussion of the treatment, its advantages, and its pitfalls.

If intramuscular fluphenazine or other similar slow-release drugs are to be used in an effective and safe way to help keep the schizophrenic out of hospital it should not be done to the detriment of two important elements of the community treat- ment of psychiatric patients : the regular support of patients and relatives, and the early detection of relapses or changes in the course of the illness.

We wish to thank Mr. Robert Wanstell, senior charge nurse, Graylingwell Hospital, who, by pointing out the depressive reaction to the drug in a patient, started off this investigation. We are also grateful to Dr. R. A. Sandison, psychiatrist to Knowle Hospital, Fareham, and Miss Barbara Nelson and Dr. B. Barraclough, of the Medical Research Council Clinical Psychiatry Unit, Graylingwell Hospital, for kindly providing notes on the suicide cases and to Mrs. Joyce Taylor for extracting the case notes at Wesham Park Hospital.

\section{REFERENCES}

Bethell, M. S., et al. (1966). British Medical fournal, 2, 1262.

Doll, R. (1969). British Medical fournal, 2, 69.

Foulds, G. A. (1960). Fournal of Mental Science, 106, 1394

Freeman, H. L. (1967). Maudsley Bequest Lecture, February 1967. Unpublished.

Fremming, K. H. (1951). The Expectation of Mental Infirmity in a Sample of the Danish Population. London, Cassell.

Hamilton, M. (1965). Clinical Trials fournal, 2, 158.

Helgason, T. (1964). Acta Psychiatrica et Neurologica Scandinavica, elgason, T. (1964).
Suppl. No. 173 .

Markowe, M., Steiner, J., and Heyworth-Davis, F. (1967). British fournal of Psychiatric Social Work, 113, 1101.

Sarwer-Foner, G. J., Sanders, S., Gomez, E., and Amadeo, M. (1966). Canadian Psychiatric Association Fournal, 2, Special Supplement.

Stengel, E., and Cook, N. G. (1958). Attempted Suicide, its Social Significance and Effects. I ondon, Oxford University Press.

Tewfik G. I. (1965). Clinical Trials fournal, 2, 150.

Venables, P. H. (1957). Fournal of Mental Science, 103, 197.

\title{
Retinopathy at Diagnosis of Diabetes, with Special Reference to Patients under 40 Years of Age
}

\author{
N. G. SOLER,* M.D. ; M. G. FITZGERALD, $\dagger$ M.D., F.R.C.P. ; J. M. MALINS, $\dagger$ M.D., F.R.C.P. \\ R. O. C. SUMMERS, $\ddagger$ M.B., M.R.C.P.
}

[With Special Plate facing p. 553]

British Medical fournal, 1969, 3, 567-569

\begin{abstract}
ummary : Diabetic retinopathy was present in $\mathbf{7 \cdot 5 \%}$ of 5,157 newly diagnosed patients seen at the Birmingham General Hospital Diabetic Clinic between 1960 and 1967. Although the condition becomes commoner with increasing age it is found in $1.5 \%$ of patients aged 20 to 39 years. The aetiology is discussed, the conclusion being that in young as in elderly diabetics asymptomatic diabetes of long duration is the main factor.
\end{abstract}

\section{Introduction}

Retinopathy is generally acknowledged to be a late complication of diabetes. Nevertheless, it is found at diagnosis in a small number of diabetics, the prevalence in different series varying from 4 to $15 \%$ (Lawrence, 1949 ; Aarseth, 1953 ; Lundbæk, 1955 ; Pyke and Roberts, 1959 ; Whittington, 1968). At the General Hospital, Birmingham, retinopathy at diagnosis has been recorded in $7.5 \%$ of patients. This figure is derived from a series of 5,157 newly diagnosed diabetics seen from 1960 to 1967.

\footnotetext{
* Commonwealth Scholar.

† Consultant Physician.

$¥$ Medical Registrar.

Diabetic Clinic, the General Hospital, Birmingham.
}

Retinal changes at diagnosis of diabetes have mainly affected older patients, and they are considered to be the result of preexisting mild diabetes of long duration (Lundbæk, 1955 ; Pyke and Roberts, 1959). In the present study, however, among the 591 patients aged 20 to 39 years nine had retinopathy at diagnosis-a prevalence of $1.5 \%$.

The purpose of the present paper is to present the figures for retinopathy at diagnosis in the various age groups and to draw particular attention to this group of younger diabetics.

\section{Method}

Patients of all age groups except children attend the General Hospital Diabetic Clinic and represent a typical hospital diabetic

\footnotetext{
TABLE I.-Classification of Diabetic Retinopathy

Stage 1: Venous dilatation and capillary microaneurysms

Stage 3: Stage 2 plus newly formed blood vessels (neovasculariza-

Stage 4: As in stage 3 with fibrotic bonds and retinal destruction
}

outpatient population. At first attendance they give their history and have a physical examination, including a neurological assessment. The fundi are examined by experienced observers in a dark room, a mydriatic being used in one eye. The ophthalmoscopic appearances are graded according to the classification of Fabrykant and Gelfand (1965) (Table I). 


\section{Findings}

The overall prevalence of retinopathy at diagnosis between 1960 and 1967 and the prevalence in various age groups are shown in Table II, the overall figure being $7.5 \%$. Retinopathy at diagnosis becomes common above 40 years of age and affects 1 in every 10 patients over 60 years of age. In the age group 20-29 years there is one patient and between 30 and 39 years there are eight patients. In addition to these nine patients under 40 years a 21 -year-old man (Case 1) more recently presented with pronounced retinopathy, and he is included in the subsequent discussion, making a total of 10 cases.

TABLE II.-Overall Prevalence of Retinopathy at Diagnosis of Diabetes from 1960 to 1967

\begin{tabular}{c|c|c|c}
\hline $\begin{array}{c}\text { Age } \\
\text { Group }\end{array}$ & $\begin{array}{c}\text { Total No. } \\
\text { of Cases }\end{array}$ & $\begin{array}{c}\text { No. with } \\
\text { Retinopathy }\end{array}$ & $\begin{array}{c}\text { Percentage with } \\
\text { Retinopathy }\end{array}$ \\
\hline $0-19$ & 124 & - & - \\
$20-29$ & 187 & 1 & $0 \cdot 53$ \\
$30-39$ & 404 & 8 & $2 \cdot 23$ \\
$40-49$ & 735 & 38 & 5.17 \\
$50-59$ & 1,382 & 98 & 7.09 \\
$60-69$ & 1,450 & 60 & 11.03 \\
$70-79$ & 718 & 14 & $9 \cdot 61$ \\
$80+$ & 146 & 1 & 9.59 \\
Not known & 11 & 389 & 9.09 \\
\hline All ages & 5,157 & & 7.54 \\
\hline
\end{tabular}

The young patients presented in a variety of ways. Four were diagnosed by routine urine testing, two following ophthalmic examination, one had a long-standing perforating ulcer of the foot, and two had boils. The one woman included in the series had pruritus vulvae, the only typical diabetic symptom reported by any patient in the under- 40 age group.

Case 1 is of particular interest. This man had no diabetic symptoms, but was referred from the Birmingham Eye Hospital after one year's visual deterioration. His knee and ankle jerks were absent but there was no other physical abnormality. His blood sugar was $595 \mathrm{mg} . / 100 \mathrm{ml}$. without ketonuria. His fundi showed dot and blot haemorrhages and exudates (Special Plate, Fig. 1). In addition an ultraviolet photograph taken

TABLE III.-Clinical Findings in Young Diabetics with Retinopathy at

\begin{tabular}{|c|c|c|c|c|c|c|c|c|c|}
\hline \multicolumn{10}{|c|}{ Diagnosis } \\
\hline $\begin{array}{l}\mathbf{g} \\
\text { Jँz }\end{array}$ & 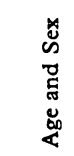 & 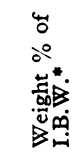 & 롤 & 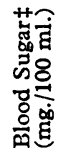 & 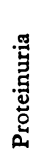 & 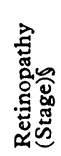 & 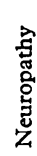 & 总 & 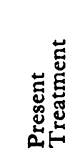 \\
\hline $\begin{array}{r}1 \\
2 \\
3 \\
4 \\
5 \\
6 \\
7 \\
8 \\
9 \\
9\end{array}$ & $\begin{array}{l}21 \\
29 \\
31 \\
32 \\
32 \\
35 \\
36 \\
37 \\
37 \\
39 \\
39 \\
39 \\
39\end{array}$ & $\begin{array}{r}+3.0 \\
+85.1 \\
+7.3 \\
-5.4 \\
+9.0 \\
+12.1 \\
+33.4 \\
-3.7 \\
+36.4 \\
+42.6\end{array}$ & $\begin{array}{l}\overline{+} \\
\overline{+} \\
\overline{+} \\
\pm \\
\overline{+} \\
\pm\end{array}$ & $\begin{array}{l}595 \\
270 \\
275 \\
375 \\
250 \\
265 \\
290 \\
255 \\
350 \\
355\end{array}$ & $\begin{array}{l}\overline{+} \\
\overline{+} \\
\overline{-} \\
\bar{z} \\
\overline{-} \\
=\end{array}$ & $\begin{array}{l}3 \\
1 \\
2 \\
2 \\
2 \\
1 \\
2 \\
1 \\
1 \\
1\end{array}$ & $\begin{array}{l}+ \\
\pm \\
+ \\
+ \\
+ \\
\pm \\
-\end{array}$ & $\begin{array}{l}140 / 70 \\
190 / 110 \\
150 / 110 \\
180 / 110 \\
135 / 85 \\
150 / 90 \\
210 / 120 \\
130 / 75 \\
150 / 90 \\
130 / 80\end{array}$ & $\begin{array}{l}\text { Insulin } \\
\text { Diet } \\
\text { Oral } \\
\text { Insulin } \\
\text { Oral } \\
\text { Insulin } \\
\text { Oral } \\
\text { Oral } \\
\text { Oral } \\
\text { Diet }\end{array}$ \\
\hline
\end{tabular}

- Society of Actuaries (1959).

† First-degree relatives only. Method N.2a.

$§$ Fabrykant and Gelfand (1965).

after intravenous fluorescein showed leaking new vessels (Special Plate, Fig. 2). The visual acuity was $6 / 24$ in his right eye and $6 / 60$ in his left eye. His diabetes is now controlled on insulin zinc suspension 20 units daily.

The relevant clinical findings in all 10 patients are shown in Table III. In five patients (Cases 5, 6, 8, 9, and 10) retinopathy was the sole abnormality. One patient (Case 1) had neuropathy in addition to retinopathy. Case 7 had neuropathy and hypertension while Cases 2 and 4 had neuropathy, proteinuria, and hypertension. Hypertension was the only abnormality detected in Case 3.

Re-examination of the fundi of nine patients in follow-up over periods ranging from 16 to 72 months has shown that the retinal appearances are unchanged in seven, have returned to normal in one, and have deteriorated in another. Case 1 is too recent for an assessment of progress.

\section{Discussion}

In previous studies estimates of the prevalence of retinopathy at diagnosis of diabetes in all age groups range from 4 to $15 \%$ (Lawrence, 1949 ; Aarseth, 1953 ; Lundbæk, 1955 ; Pyke and Roberts, 1959 ; Whittington, 1968). Many factors contribute to the variation in these results, including patient selection, the examiner's diligence, and the conditions of examination. It is likely that cases pass unrecognized, and $7.5 \%$ in the present series is probably an underestimate. The patients with retinopathy at diagnosis in published series are for the most part elderly. Lundbæk (1955) and Pyke and Roberts (1959), who have discussed the problem, agree that their findings are consistent with diabetes that has been mild but of long standing and that there is no reason to contradict the general belief that duration of diabetes is the main factor in the development of retinopathy.

Colwell (1966), reviewing the literature, noted that retinopathy is rarely recorded in the first five years of diabetes in younger patients. Aarseth (1953) mentioned that two patients in age group 20-39 years developed retinopathy within five years of diagnosis. Lundbæk (1955) and Kornerup (1955) in their respective series have not recorded retinopathy at diagnosis under 40 years of age, while Pyke and Roberts (1959) have one patient. On the other hand, Whittington (1968) stated that $3 \%$ of patients under 40 years have retinopathy at diagnosis as compared with $1.5 \%$ in the present study.

The presence of retinopathy at diagnosis in young patients raises the question whether factors other than unrecognized diabetes as such can explain the condition. It could be argued that vascular lesions have proceeded independently of any overtly disturbed carbohydrate metabolism, and that this might explain the lack of diabetic symptoms. There is, however, no support for such a theory from our results, as 9 out of 10 patients were still asymptomatic at diagnosis and yet the blood sugar was higher than $250 \mathrm{mg} . / 100 \mathrm{ml}$. in all cases.

As 7 of the 10 patients are controlled on diet or oral therapy it may appear that their diabetes is milder than that of other young diabetics. A study of patients from this clinic in a similar age group, however, shows that their treatment in the first two years after diagnosis does not differ appreciably from that of the present group of patients (Table IV).

TABLE IV.-Percentage on Various Treatments at Different Ages at Diagnosis of Diabetes in 1962 and 1963 and One and Two Years Later

\begin{tabular}{c|c|c|c|c|c|c}
\hline $\begin{array}{c}\text { Years } \\
\text { following } \\
\text { Diagnosis } \\
\text { of Diabetes }\end{array}$ & \multicolumn{3}{|c|}{$\begin{array}{c}\text { 20-29 Years } \\
\text { (36 Patients) }\end{array}$} & \multicolumn{3}{|c}{$\begin{array}{c}\text { 30-39 Years } \\
\text { (58 Patients) }\end{array}$} \\
\hline Insulin & Oral & Diet & Insulin & Oral & Diet \\
\hline 0 & 61 & 28 & 11 & 21 & 49 & 30 \\
1 & 66 & 23 & 11 & 28 & 42 & 30 \\
2 & 66 & 25 & 9 & 30 & 44 & 26 \\
\hline
\end{tabular}

There is also no evidence of an accelerated type of diabetic retinopathy. The rapid deterioration expected if this were the case is not borne out by reassessment of the fundi. This agrees with the findings of Pyke and Roberts (1959) in older diabetics.

The facts available do not favour the idea that we are reporting a group distinct from younger diabetics of the same age. As in the case of elderly patients with retinopathy at diagnosis they were almost symptom-free and most of them are controlled on oral therapy. The presence of neuropathy and proteinuria at diagnosis in some of them suggests a long-standing process. It is therefore possible that these young patients, like their older 
counterparts. may have had asymptomatic diabetes of long duration.

It is well known but not sufficiently recognized that the onset of diabetes often precedes the diagnosis by years rather than weeks or months, and it is wrong to suppose that the onset of symptoms, however acute, indicates the date when the disease first appeared. Our findings suggest that this may be true even in young patients.

This study was supported by a grant from the British Diabetic Association.

\section{REFERENCES}

Aarseth, S. (1953). Acta Medica Scandinavica, Suppl. No. 281, p. 1. Society of Actuaries (1962). In Documenta Geigy, Scientific Tables, 6th ed., edited by K. Diem, p. 623. Manchester, Geigy.

Colwell, J. A. (1966). Diabetes, 15, 497.

Fabrykant, M., and Gelfand, M. L. (1965). American fournal of Medical Sciences, 250, 513 .

Kornerup, T. (1955). Acta Medica Scandinavica, 153, 81.

Lawrence, R. D. (1949). Lancet, 2, 401.

Lundbæk, K. (1955). Acta Medica Scandinavica, 152, 53.

Pyke, D. A., and Roberts, D. St. C. (1959). Acta Medica Scandinavica, $163,489$.

Whittington, T. H. (1968). In Clinical Diabetes and its Biochemical Basis, edited by W. G. Oakley, D. A. Pyke, and K. W. Taylor, p. 476. Oxford, Blackwell Scientific Publications.

\section{Medical Memoranda}

\section{Regional Blood Flow in Internal Carotid Distribution during Migraine Attack}

\author{
[With Special Plate Facing p. 553]
}

British Medical Fournal, 1969, 3, 569-570

According to the classical theory the first (prodromal) phase in migraine is caused by ischaemia within the internal carotid system and the second phase (headache) by a vasodilatation, especially within the external carotid system. The extracranial vasodilatation and increase in arterial pulse pressure has been elegantly demonstrated by Wolff (1963). The pathological processes within the internal carotid system, however, have until recently escaped quantitative description.

Dukes and Vieth (1966) reported the case of a patient who developed a migraine attack during an angiographic study. They reported a progressive decrease in the filling of the internal carotid system during the prodromal phase when scotomata were present. The angiogram returned to normal during the succeeding headache. They concluded that their findings supported the classical theory. The demonstrated angiographic changes, however, could have resulted from a lowering of $\mathrm{PaCO}_{2}$ by hyperventilation. This possibility was not considered and $\mathrm{PaCO}_{2}$ levels were not reported.

O'Brien (1967), using a xenon-133 inhalation technique, reported a reduction of about $20 \%$ in the " cerebral cortex perfusion" rate of seven patients during the prodromal phase of migraine attacks. This flow method has certain quantitative limitations, and, furthermore, it does not exclude changes of blood flow in the external carotid system. This latter point seems crucial to a proper understanding of the migraine syndrome.

The intracarotid xenon-133 injection method (Lassen et al., 1963 ; Høedt-Rasmussen et al., 1966) permits an accurate and specific measurement of the regional cerebral blood flow. The modification of the method as used here is described elsewhere (Høedt-Rasmussen et al., 1967 ; Paulson et al., 1969). Briefly, the method consists in introducing a thin polyethylene catheter into the internal carotid artery, and the rapid injection of about $2 \mathrm{mCi}$ of xenon-133 in 1-2 ml. of saline through the catheter. The clearance of the isotope from the brain is recorded from 16 areas with multiple external scintillation detectors, and the regional cerebral blood flow values are calculated from the initial slope of the clearance curves. The catheter and the injections of xenon have been shown not to interfere with the cerebral haemodynamics.

This technique was employed in connexion with an angiographic examination of the patient having severe migraine attacks. These investigations were done in order to rule out other intracranial morbidity. He was asymptomatic at the time of carotid puncture and during the two initial regional cerebral blood flow measurements. Fortuitously, he then developed his usual prodromal symptoms, which consisted of tactile disturbances in his right hand, agnosia, and total apraxia-without paresis. At the same time he had aphasic difficulties, especially of the central and parietal lobe type, and a slight disorientation. The two initial regional cerebral blood flow measurements showed no abnormalities. Regional cerebral blood flow measurements during the prodromal phase revealed a pronounced flow reduction in the entire internal carotid system, especially in the parietal lobe and in the upper part of the temporal lobe-that is, from the regions which would explain his symptoms (Fig. I). The quantitative flow values in these

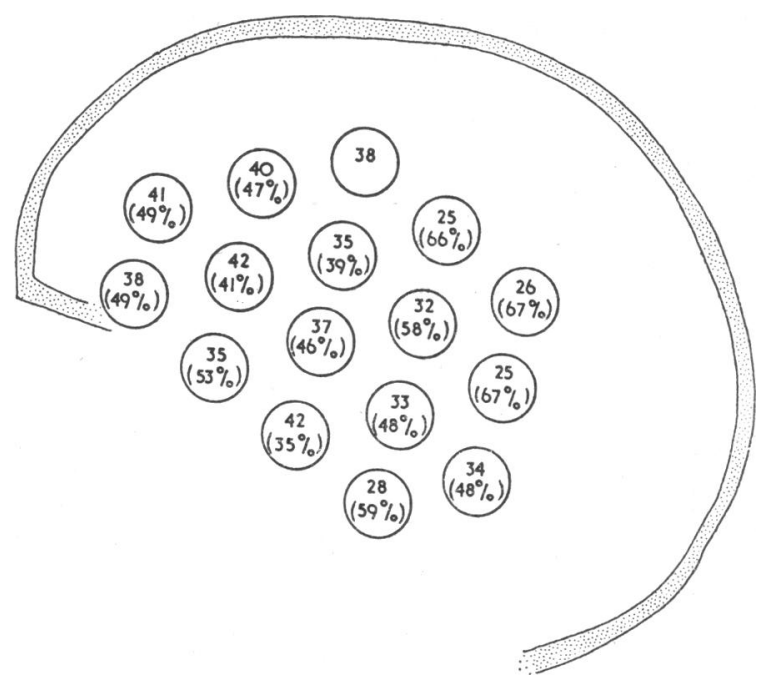

FIG. I.-Regional cerebral blood flow in $\mathrm{ml} / / 100 \mathrm{~g} . / \mathrm{min}$. during the prodromal phase of migraine and, in parentheses, the percentage decrease from the previous state.

regions reached a level which is known to be critical for a normal oxygenation (Alexander et al., 1968). Although the patient hyperventilated and his arterial $\mathrm{PCO}_{2}$ was reduced from 40 to $34 \mathrm{~mm}$. $\mathrm{Hg}$, this mild hypercapnia could account for only a flow reduction of about $15 \%$ (Reivich, 1964).

An angiographic examination was performed immediately after these regional cerebral blood flow measurements, when his prodromal symptoms were most intense. The angiogram, as seen in Fig. 1 (Special Plate), was quite normal and no arterial spasm was present.

A normal angiogram together with a reduced regional cerebral blood flow value indicates that the cerebral vascular 